\title{
Research on Quantitative Models of Electric Vehicle Charging Stations Based on Principle of Energy Equivalence
}

\author{
Zhenpo Wang, ${ }^{1}$ Peng Liu, ${ }^{2}$ Jia Cui, ${ }^{1}$ Yue Xi, ${ }^{1}$ and Lei $\mathrm{Zhang}^{1}$ \\ ${ }^{1}$ School of Mechanical and Vehicular Engineering, Beijing Institute of Technology, Beijing 10081, China \\ ${ }^{2}$ Key Laboratory of Power Electronics and Electric Drive, Institute of Electrical Engineering, Chinese Academy of Sciences, \\ Beijing 100190, China
}

Correspondence should be addressed to Zhenpo Wang; wangzhenpo@bit.edu.cn

Received 8 June 2013; Revised 25 July 2013; Accepted 28 July 2013

Academic Editor: Wuhong Wang

Copyright ( 2013 Zhenpo Wang et al. This is an open access article distributed under the Creative Commons Attribution License, which permits unrestricted use, distribution, and reproduction in any medium, provided the original work is properly cited.

\begin{abstract}
In order to adapt the matching and planning requirements of charging station in the electric vehicle (EV) marketization application, with related layout theories of the gas stations, a location model of charging stations is established based on electricity consumption along the roads among cities. And a quantitative model of charging stations is presented based on the conversion of oil sales in a certain area. Both are combining the principle based on energy consuming equivalence substitution in process of replacing traditional vehicles with EVs. Defined data are adopted in the example analysis of two numerical case models and analyze the influence on charging station layout and quantity from the factors like the proportion of vehicle types and the EV energy consumption at the same time. The results show that the quantitative model of charging stations is reasonable and feasible. The number of EVs and the energy consumption of EVs bring more significant impact on the number of charging stations than that of vehicle type proportion, which provides a basis for decision making for charging stations construction layout in reality.
\end{abstract}

\section{Introduction}

In the transportation sector, the widespread use of the combustion engine vehicles has become an important factor of energy consumption and environmental pollution $[1,2]$, which leads the EV to get more attention owing to its distinguished features of genuine zero emission and high efficiency $[3,4]$. In China, the EV has become an essential part of the new energy strategy and smart grid field $[5,6]$. The State Council of China has defined the EV as a new strategic industry [7]. Thus, the electric vehicle will become the focus of Chinese automotive industry and energy industry in the future.

EV charging station is an important supportive infrastructure to boost the market acceptance and popularity of EVs $[8,9]$, because the accessibility and convenience of charging stations would impose significant influence on consumers' decisions due to the inherent demand of periodic charging $[10,11]$. Currently, relative research has been a hot topic and received increasing interest and dedicated effort from researchers and practitioners. Hatton et al. [12] pointed out that the construction of charging facilities' network was of great significance for the EV market expansion and described a variety of charging facility construction modes as well as their necessary requirements. Wang et al. [13] proposed a multiobjective planning model, which takes factors such as characters of charging station, characters of charging consumers, distribution of the charging demands, power grid, and municipal planning into account. Revelle and Eiselt [14] established a classical location model and adjusted the model by using different constraints. Wang et al. [15] researched on matching theory of EV charging stations. Johannes et al. [16] established a dynamic spatial model of the development of a charging infrastructure for EVs to allocate the need for charging stations in space. He et al. [17] established EV charging station's minimum comprehensive cost model. Feng et al. [18] presented a novel method for EV charging station planning based on the weighted Voronoi diagram. Ning et al. [19] analyzed the economy of batteryswapping charging mode, which is one of the factors on the charging stations construction layout. However, in the field of the location of EV charging stations, there was not enough analysis on quantitative model, and the layout 
planning system of charging station has not been formed yet.

Since the charging time of electric vehicles is longer than conventional fuel vehicles, taking up a longer time for parking, the planning and layout of the charging stations are subject to geographical location conditions, including distribution capacity, available space, time of waiting for charging, peripheral facilities, and many other factors, especially the cities with larger population density and scarce land resources. If geographical conditions permit, theoretical research of charging station construction and planning and its scale and influencing factor analysis is a relative effective planning measure at the early stage of electric vehicles. The network planning of charging stations in Beijing in which the author participated is also done based on this idea.

In this paper, a quantitative model and a location model along intercity road are established by introducing some parameters such as regional coefficients of variation and attraction coefficient of charging stations, which are all based on the principle of energy equivalence. Aiming at designing the layout of urban charging stations, a quantitative model has been established based on the oil sales transaction. The correctness and effectiveness of models are further proved by case studies. The influence and sensitivity of the factors including the number of EVs, the proportion of vehicle type, and the electricity consumption of EVs are analyzed.

\section{Quantitative Model of Electric Vehicle Charging Stations}

2.1. Quantitative Model of Charging Stations along Intercity Roads. Quantitative model of charging stations along intercity roads is proposed based on the consumption of typical linear roads. That is, the road system is assumed to be composed of a main line and a bunch of forks which divided the region into several sections [20]. In order to simplify the model, forks of the road should not be too many, which indicates that the theory is not applicable to the layout planning of charging stations in urban area. However, it has a good applicability to typical intercity roads such as highways, national highways, and provincial highways.

\subsubsection{Parameter Definitions}

(1) Length of Road $(\mathrm{km}, \mathrm{L})$. The length of road is selected to establish the model.

(2) Traffic Flow of Road (Vehicles/Day, V). It denotes the number of vehicles that pass the road $L$ in a certain time, coming from the result of statistics. The traffic flow of vehicle type $i(1 \leq i \leq N)$ is expressed as $V_{i}$.

(3) Power Consumption per $100 \mathrm{~km}$ of EVs ( $\mathrm{kWh} / \mathrm{km}, \mathrm{Q})$. The statistics of average power consumption per $100 \mathrm{~km}$ of EVs is used to convert into average power consumption per kilometer which can be indicated by $C_{y}$.

(4) Regional Coefficient of Variation $\left(C_{d}\right)$. The conditions of different roads used by the model are various. For instance, the average power consumption per $100 \mathrm{~km}$ in mountainous regions and plains is different. Therefore, a regional coefficient of variation $\left(C_{d}\right)$ is introduced to regulate the average power consumption per $100 \mathrm{~km}$ in the model. This parameter comes from statistics.

(5) Distance between Charging Stations $(\mathrm{km}, \mathrm{L})$. The distance between two adjacent charging stations is calculated to ensure the charging stations to make a certain profit. In order to make sure that at least charging stations are not at a loss, the minimum distance is defined as $l_{\min }$.

(6) Zero Profit Daily Electricity Sales of a Charging Station $(k W h)$. The zero profit daily electricity sales of a charging station $\left(W_{0}\right)$ is figured out based on the cost of the charging station (hardware costs, service costs, daily expenses, and other factors) and the electricity sales profit.

(7) Attraction Coefficient of a Charging Station $\left(C_{y}\right)$. In practice, customers tend to choose better-equipped charging stations offering higher-quality service at a lower cost when their EVs need to be charged. If attraction coefficient of a charging station was not introduced, the calculated distance between two charging stations would be shorter, which could lead to low profits or losses, resulting in a waste of social resources. This parameter comes from statistics. It is the ratio of actual electricity sales of charging stations and the theoretical power consumption of EVs in a certain road.

(8) Expected Daily Electricity Sales of a Charging Station $\left(k W h, W_{q}\right)$. Expected daily electricity of a charging station is the electricity that the charging station expects to sell every day. This parameter comes from statistics.

(9) There Are M Forks of the Road. These $M$ forks divided the road into $M-1$ short sections; each short section has no forks of the road, so that the traffic flow of this section is uniform. $V_{i, j}$ can be defined as the traffic volume of vehicle type ( $i$ ) of the road $\left(L_{j}\right)$. This parameter comes from statistics.

\subsubsection{Assumptions}

(1) Zero Profit Electricity Sales in the Same Level of Charging Stations Are Equal. The daily zero profit electricity in a charging station will be influenced by plenty of factors including the scale of the charging station, the number of workers, service levels, and equipment costs. However, in order to simplify the calculation, it is assumed that the zero profit electricity sales in the same level of charging stations are equal in the modeling process.

(2) EVs are recharged in accordance with the principle of proximity and needs, which means that the charging pattern accords with the condition that the EV needs to be recharged when the remaining energy reaches the alert value and the energy can be filled up each time, ignoring other factors.

Under this assumption, only the position factor is taken into consideration. Actually, when EVs need electricity supply, drivers will certainly choose the cheaper and larger 
ones with higher quality services. This may contribute to drivers' violation towards the principle of proximity and needs when they want to recharge their EVs. This will inevitably lead to a shorter distance between the charging stations which are calculated based on the model. In order to make the model more practical, $C_{y}$ (attraction coefficient of a charging station) is introduced when modeling, so that the electricity sales in the section $L$ is equivalent to total energy consumption $\times C_{y}$.

(3) The Charging Electricity Level of EVs on the Road Is Equal to the Energy Consumption on the Road $\times$ Attraction Coefficient of a Charging Station. Right now, road $L$ is selected as an object of study. It will be verified from the simple case at the beginning that the selected road should not be too long, so that the EV will be recharged only once at most in a certain road.

For any chosen $\mathrm{EV}, w(\mathrm{kWh})$ is the control remaining electricity in the battery and $W(\mathrm{kWh})$ is the fully charged battery level. When the EV runs on road $L$, battery storage of electricity $(W(x))$ is between $w$ and $W, w<W(x)<W$. The power consumption of the EV in this section is expressed as $W(L)$, so the remaining battery level of this EV is $W(x)-W(L)$ when it leaves this section. Then, if $W(x)-W(L)<w$, the EV must be recharged on the road, and the complementary power is expressed as $W-w$; when leaving the road the remaining battery level of the $\mathrm{EV}$ is

$$
W_{s}=W(x)-W(L)+W-w .
$$

When $W(x)-W(L)>w$, the EV will not need to be charged at the charging station along this road. If $W(x)-$ $W(L)<w$, it means $w<W(x)<w+W(L)$, and the EV must be charged in the charging station in this section. The complementary energy is $W-w$.

Assuming that reduce rate of the battery energy is proportional to the driving distance for EVs and because the selection of the section is arbitrary, the $W(x)$ will be distributed uniformly between $w-W$. Under this assumption, the probability of EV charged on the road is

$$
P_{W(x) \mid w<W(x)<w+W(L)}=\frac{W(L)}{W-w} .
$$

Thus, the charged electricity of the EV on the road is

$$
(W-w) \times \frac{W(L)}{W-w} \times C_{y}=W(L) \times C_{y} .
$$

The charging electricity of the EV on the toad is equal to the consumption of energy $\times$ attraction coefficient of charging station.

Then, charge electricity of all EVs passed through the road equals $\sum W(L) \times C_{y}$. Additionally, if the EVs are recharged more than once because of the overlong selected road, the road could be divided into many sections, the EV would be recharged only once in each section. It is proved right in every short section, so the assumption is still valid.

2.1.3. Modeling. (1) $W_{Q_{i, j}}$ is the electricity consumption of the EV $i$ in the road $L_{j}$. Taken the attraction coefficient of a charging station and regional coefficient of variation and other factors into consideration, the result is shown in the following:

$$
W_{Q_{i, j}}=Q_{i} \times C_{d} \times L_{j} \times V_{i, j} \times C_{y} .
$$

(2) The electricity consumption $\left(W_{Q_{j}}\right)$ of all the EVs in the road $L_{j}$ is expressed as the summation of the electricity consumption of all types of EVs in this section, as shown in the following:

$$
\begin{aligned}
W_{Q_{j}} & =\sum_{i=1}^{N} W_{Q_{i, j}} \\
& =\sum_{i=1}^{N}\left(Q_{i} \times C_{d} \times L_{j} \times V_{i, j} \times C_{y}\right) \\
& =C_{d} \times L_{j} \times C_{y} \times \sum_{i=1}^{N}\left(Q_{i} \times V_{i, j}\right) .
\end{aligned}
$$

From the above, the total electricity consumption of all EVs in the section $L$ is defined as

$$
\begin{aligned}
W_{Q} & =\sum_{j=1}^{M} W_{Q_{j}} \\
& =\sum_{j=1}^{M}\left(C_{d} \times L_{j} \times C_{y} \times \sum_{i=1}^{N}\left(Q_{i} \times V_{i, j}\right)\right) \\
& =C_{d} \times C_{y} \times \sum_{j=1}^{M}\left(L_{j} \times \sum_{i=1}^{N}\left(Q_{i} \times V_{i, j}\right)\right) .
\end{aligned}
$$

(3) According to assumption (3) in Section 2.1.2, electricity sales on the road $L$ equal the electricity consumption $\times$ the attraction coefficient of a charging station. Because it is assumed that, in Section 2.1.2 (1), the same level of charging stations is equal to the zero profit electricity sales, when the zero profit electricity sales of a charging station is $W_{0}$, the maximum number of permitted charging stations is the ratio of the total electricity sales and zero profit electricity sales, as shown in the following:

$$
\begin{aligned}
z_{\max } & =\frac{W_{Q}}{W_{0}} \\
& =\frac{C_{d} \times C_{y} \times \sum_{j=1}^{M}\left(L_{j} \times \sum_{i=1}^{N}\left(Q_{i} \times V_{i, j}\right)\right)}{W_{0}} .
\end{aligned}
$$

(4) Average distance between the charging stations is the ratio of the length and the number of charging stations in a section, as shown the following:

$$
\begin{aligned}
l_{\min } & =\frac{L}{z_{\max }} \\
& =\frac{L \times W_{0}}{C_{d} \times C_{y} \times \sum_{j=1}^{M}\left(L_{j} \times \sum_{i=1}^{N}\left(Q_{i} \times V_{i, j}\right)\right)} .
\end{aligned}
$$


(5) Assuming that a charging station is at any point along the road $L_{j}, W_{q}$ is defined as the expected sales electricity of charging stations, and $l_{j}$ is expressed as the control distance from the upstream charging station, based on assumption (3) and formula (7), $W_{Q_{j}}$ can be defined as

$$
\begin{gathered}
W_{\mathrm{Q}_{j}}=C_{d} \times l_{j} \times C_{y} \times \sum_{i=1}^{N}\left(Q_{i} \times V_{i, j}\right), \\
W_{\mathrm{Q}_{j}}=W_{q} .
\end{gathered}
$$

Scilicet,

$$
\begin{gathered}
C_{d} \times l_{j} \times C_{y} \times \sum_{i=1}^{N}\left(Q_{i} \times V_{i, j}\right)=W_{q}, \\
l_{j}=\frac{W_{q}}{C_{d} \times C_{y} \times \sum_{i=1}^{N}\left(Q_{i} \times V_{i, j}\right)} .
\end{gathered}
$$

2.2. Quantitative Model of Charging Stations in a Certain Area. According to the number of gas stations and average data of daily oil sales in a certain area, the data of average daily oil sales of all gas stations are translated into average daily electricity sales of charging stations through introducing conversion coefficient. The average daily electricity sales will be the expected average daily electricity sales when the EVs are popularized in a certain area in the future. Based on the electricity sales level of charging stations, the quantitative model of charging stations in a certain area can be established.

\subsubsection{Parameter Definitions}

(1) Daily Oil Sales of a Gas Station $\left(L, O_{i}\right)$. This parameter is defined as the daily oil sales in a gas station, which comes from statistics. It is calculated from the data of yearly oil sales divided by the number of days of a year. By this way, the fluctuation of the data due to the changes of seasons, weather, traffic flow, and other random factors can be reduced.

(2) Daily Electricity Sales of a Charging Station $\left(k W h, E_{i}\right)$. This parameter is defined as the daily electricity sales of a charging station in the selected area, which can be figured out.

(3) The Proportional Coefficient of the Corresponding Oil Sales and Electricity Sales $\left(k W h / L, I_{i}\right)$. The proportional coefficient is the total oil sales and corresponding electricity sales which are converted out by calculation.

(4) The Number of Gas Stations Is $M(1 \leq i \leq M)$. This parameter is the number of gas stations in a certain area which will be calculated.

(5) Average Oil Consumption per $100 \mathrm{~km}$ of Traditional Vehicles $\left(L / 100 \mathrm{~km}, G_{j}\right)$. The parameter is defined as an average oil consumption per $100 \mathrm{~km}$ of the main vehicles which fuel up in the gas station, ignoring the vehicles that seldom fuel up in the gas station in a certain area. The numbers come from statistics.

(6) Average Electricity Consumption per $100 \mathrm{~km}$ of EVs $\left(k W h / 100 \mathrm{~km}, Q_{j}\right)$. The parameter is defined as the electricity consumption per $100 \mathrm{~km}$ of EVs which is corresponded to the main types of traditional vehicles, which comes from statistics.

(7) The Proportional Coefficient of Fuel Consumption and Electricity Consumption of Corresponding Types of Vehicles $\left(k W h / L, I_{j}\right)$. The parameter is a proportional coefficient of the fuel consumption per $100 \mathrm{~km}$ of traditional vehicle and the electricity consumption of corresponding EVs. This parameter will be figured out.

(8) The Number of Types of Vehicles Entering the Gas Station $(N, 1 \leq j \leq N)$. The parameter is used for the classification of the main vehicles which are fuelled up in a certain area, ignoring the vehicles which are seldom fuelled up in the gas stations in the certain area.

(9) The Proportion of Vehicle Types $\left(D_{j}\right)$. This parameter is the proportion of vehicles of various types, which is from statistics.

(10) The Proportion of Users Charging in the Charging Station $\left(C_{c d}, 0<C_{c d} \leq 1\right)$. Since the users may charge at home or residential parking, this parameter needs to be introduced. It is the proportion of the energy getting from the charging station.

(11) Zero Profit Daily Electricity Sales of a Charging Station $\left(k W h, W_{0}\right)$. This parameter is defined the same as the one in Section 2.2.1(6).

(12) Expected Daily Electricity Sales of a Charging Station $\left(k W h, W_{q}\right)$. This parameter is defined the same as the one in Section 2.2.1 (8).

2.2.2. Modeling. (1) The proportional coefficient $I_{j}$ is the ratio of electricity consumption and fuel consumption. It equals the ratio of electricity consumption per $100 \mathrm{~km}$ of EVs and fuel consumption per $100 \mathrm{~km}$ of refueling vehicles. It is shown in the following:

$$
I_{j}=\frac{Q_{j}}{G_{j}} .
$$

(2) The proportional coefficient $I_{i}$ is the ratio of oil sales of gas stations and electricity sales of charging stations. It equals the summation of the product of the proportion of different EV types and the corresponding proportional coefficient $I_{j}$. It is shown in the following:

$$
I_{i}=\sum_{j=1}^{N}\left(D_{j} I_{j}\right), \quad \sum_{j=1}^{N} D_{j}=1, \quad I_{i}=\frac{E_{i} / C_{c d}}{O_{i}} .
$$

(3) The daily electricity sales of a charging station $\left(E_{i}\right)$ is a integrated result, which takes factors such as proportion of 
TABLE 1: Data of traffic flow in each section.

\begin{tabular}{lccccc}
\hline Section & Length $(\mathrm{km})$ & $\begin{array}{c}\text { Traffic flow } \\
\text { (vehicle/d) }\end{array}$ & $\begin{array}{c}\text { Traffic flow of } \\
\text { EVs (vehicle/d) }\end{array}$ & $\begin{array}{c}\text { Traffic flow of } \\
\text { passenger EVs } \\
\text { (vehicle/d) }\end{array}$ & $\begin{array}{c}\text { Traffic flow of } \\
\text { commercial EVs } \\
\text { (vehicle/d) }\end{array}$ \\
\hline AB & 7.1 & 34614 & 3462 & 2770 & 692 \\
BC & 2.36 & 32300 & 3230 & 2584 & 646 \\
CD & 10.95 & 27661 & 2766 & 2213 & 553 \\
DE & 2.9 & 29797 & 2980 & 2384 & 596 \\
\hline
\end{tabular}

the user charging in charging stations and the oil sales into account:

$$
E_{i}=C_{c d} O_{i} I_{i}=C_{c d} O_{i} \sum_{j=1}^{N}\left(D_{j} I_{j}\right)=C_{c d} O_{i} \sum_{j=1}^{N}\left(D_{j} \frac{Q_{j}}{G_{j}}\right) .
$$

(4) From the above, the sum of the daily electricity sales of charging stations in a certain area can be acquired. And it is defined as

$$
\begin{aligned}
E & =\sum_{i=1}^{M} E_{i} \\
& =\sum_{i=1}^{M}\left(C_{c d} O_{i} \sum_{j=1}^{N}\left(D_{j} \frac{Q_{j}}{G_{j}}\right)\right) \\
& =C_{c d} \sum_{i=1}^{M}\left(O_{i} \sum_{j=1}^{N}\left(D_{j} \frac{Q_{j}}{G_{j}}\right)\right) .
\end{aligned}
$$

Then the maximum permitted number of charging stations in the certain area $z_{\max }$ is defined as

$$
z_{\max }=\frac{E}{W_{0}}=\frac{C_{c d} \sum_{i=1}^{M}\left(O_{i} \sum_{j=1}^{N}\left(D_{j}\left(Q_{j} / G_{j}\right)\right)\right)}{W_{0}} .
$$

The proper amount of charging stations that will be built in the certain area is defined as

$$
z_{j y}=\frac{E}{W_{q}}=\frac{C_{c d} \sum_{i=1}^{M}\left(O_{i} \sum_{j=1}^{N}\left(D_{j}\left(Q_{j} / G_{j}\right)\right)\right)}{W_{q}} .
$$

It can be seen from the modeling process that the model is based on the proportion of the oil consumption of traditional vehicles and the energy consumption of corresponding EVs, and then the conversion coefficient of the oil sales and the electricity sales can be worked out by statistical method and weighting mathematical method. Finally, the potential demand for electricity of EVs in a certain area can be calculated according to the conversion coefficient.

\section{Analysis on the Model Influencing Factors}

To verify the validity of the model and analyze its influencing factors, some examples are computed and analyzed by using typical road traffic flow and the number of regional gas stations as basic parameters, and the sensitivity of the parameters needs to be analyzed and quantified.

\subsection{Example of the Quantitative Model of Charging Stations along Intercity Road}

3.1.1. Settings of Basic Parameters. For example [21], the total length of one section of highway is $23.3 \mathrm{~km}$, there are five entrances or exits (points $\mathrm{A}, \mathrm{B}, \mathrm{C}, \mathrm{D}$, and $\mathrm{E}$ ) dividing it into four sections, and the length and traffic flow data of each section are shown in Table 1. Assuming that the proportion of EVs could be $10 \%$ of the total number, the proportion of passenger EVs and commercial EVs is $4: 1$, and the traffic flow data of EVs is shown in Table 1, too.

According to the statistics of electricity consumption per $100 \mathrm{~km}$ of a EV in $[22,23]$, the electricity consumption per $\mathrm{km}$ of a passenger EV is calculated as $Q_{1}=0.25 \mathrm{kWh} / \mathrm{km}$ and the electricity consumption per kilometer of a commercial EV is calculated as $Q_{2}=1.22 \mathrm{kWh} / \mathrm{km}$.

The regional coefficient of variation is defined as $C_{d}=$ 0.85 , and the attraction coefficient of charging stations is defined as $C_{y}=0.8$.

Referring to "Technical specifications of electricity supply and assurance for electric vehicle: electric vehicle charging station" [24], the data of zero profit electricity sales of the tertiary charging station is introduced, which can provide service to $100 \mathrm{EVs}$ per day. It is assumed that each EV can be charged for $100 \mathrm{kWh}$ each time, so the daily maximum sales of a charging station is $10000 \mathrm{kWh}$. Assuming that the zero profit daily sales is $60 \%$ of the maximum daily sales and the expectation daily sales is $90 \%, W_{0}$ is $6000 \mathrm{kWh}$ and $W_{q}$ is $9000 \mathrm{kWh}$.

3.1.2. Calculations of the Number of Charging Stations along the Intercity Road. (1) The electricity consumption in each section and the total consumption of the passenger EVs and commercial EVs are calculated, respectively, according to (4) and (5), and the results are shown in Table 2.

The total electricity sales in section $\mathrm{AE}$ are calculated as $W_{\mathrm{Q}}=21473.07 \mathrm{kWh}$, and then the maximum permitted number of charging stations is figured out as $z_{\max }=$ $21473.07 / 6000=3.58$; it could be rounded up to an integer $\left(z_{\max }=4\right)$. The average length between the charging stations can be figured out as $I_{\min }=23.3 / 4=5.825 \mathrm{~km}$.

(2) In order to obtain a satisfactory benefit, traffic flow and electricity consumption expectation sales should be taken into account when making the layout plan. It is assumed that there is a charging station in section $\mathrm{BC}$, and the control distance with the upstream charging station could be calculated as shown in Table 3. 
TABLE 2: Data of electricity consumption in each section.

\begin{tabular}{lccc}
\hline Section & $\begin{array}{c}\text { Electricity } \\
\text { consumption of } \\
\text { passenger EVs } \\
(\mathrm{kWh})\end{array}$ & $\begin{array}{c}\text { Electricity } \\
\text { consumption of } \\
\text { commercial EVs } \\
(\mathrm{kWh})\end{array}$ & $\begin{array}{c}\text { Total electricity } \\
\text { consumption } \\
(\mathrm{kWh})\end{array}$ \\
\hline $\mathrm{AB}$ & 3343.39 & 4075.99 & 7419.38 \\
$\mathrm{BC}$ & 1036.70 & 1264.78 & 2301.48 \\
$\mathrm{CD}$ & 4119.50 & 5023.52 & 9143.02 \\
$\mathrm{DE}$ & 1175.31 & 1433.88 & 2609.19 \\
\hline
\end{tabular}

TABLE 3: Layout of charging stations.

\begin{tabular}{lcc}
\hline No. & 1 & 2 \\
\hline Control distance $(\mathrm{km})$ & 9.38 & 9.63 \\
Control coordinate $(\mathrm{km})$ & 9.38 & 19.01 \\
\hline
\end{tabular}

TABLE 4: Data of charging stations in different proportions of vehicle type.

\begin{tabular}{lll}
\hline Proportion of vehicle type & $z_{\max }$ & $l_{\min }$ \\
\hline $9: 1$ & 2.80 & 8.32 \\
$4: 1$ & 3.58 & 6.51 \\
$7: 3$ & 4.36 & 5.34 \\
\hline
\end{tabular}

According to this result, defined amount of charging stations in this section is 2 . If the number was more than two, the control coordinate would exceed the length of the road, which deviates from actuality. Therefore, this scheme is the best choice. This case study has shown that the quantitative model of charging stations along the intercity road is reasonable and feasible, which can help making layout plan for charging stations in a typical road.

3.1.3. Analysis of Influencing Factors on the Number of the Charging Stations along Intercity Road. (1) Proportion of vehicle type influence on the number of charging stations along intercity road.

Supposing that other parameters are constant values, the numbers of charging stations are calculated respectively when the proportions of passenger vehicles and commercial vehicles are $9: 1$ and $7: 3$. Table 4 shows the consequence which also demonstrates the corresponding data in Section 3.1.2.

The data in Table 4 shows that the amount of charging stations increases with the reduction of the proportion of commercial vehicles. With the proportion of the commercial vehicles increasing by $10 \%$ each time, the maximum number of permitted charging stations $\left(z_{\max }\right)$ would become 3.58 and 4.36 , increased by $27.6 \%$ and $21.7 \%$, respectively.

(2) The number of EVs influences the number of charging stations along intercity road.

It is assumed that other parameters are constant values. Data of $15 \%$ and $20 \%$ of the total traffic flow are used, respectively, to represent the number of EVs in this calculation. Table 5 shows the consequence.

Table 5 shows that the maximum permitted number of charging stations increases significantly and the average
TABLE 5: Data of charging stations under the condition of different numbers of EVs.

\begin{tabular}{lcc}
\hline Proportion of EVs & $z_{\max }$ & $l_{\min }$ \\
\hline $10 \%$ & 3.58 & 6.51 \\
$15 \%$ & 5.36 & 4.35 \\
$20 \%$ & 7.13 & 3.27 \\
\hline
\end{tabular}

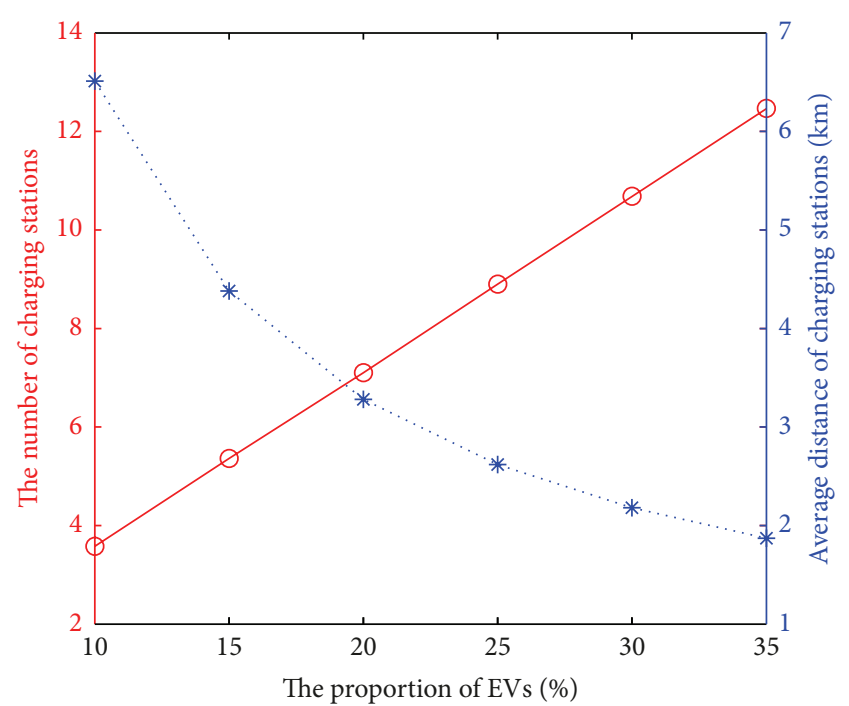

$$
\begin{array}{ll}
\odot-z_{\max } \\
* \cdots l_{\min }
\end{array}
$$

FIgURE 1: Data of charging stations in different number of EVs.

distance between the charging stations becomes shorter as the number of EVs increases. With the number of EVs increasing by $5 \%$, the maximum number of charging stations would add 1.78 and 3.55 which is relative to the original data, respectively, which means a linear growth of $49 \%$ and $99 \%$. Consequently, the number of EVs has remarkable influence on the number of charging stations in the case of a certain scale of charging stations. It means that the number of EVs is a sensitive factor on the charging stations planning.

With the development of EV market, the number of EVs will increase continuously. The conditions of different numbers of EVs $(25 \%, 30 \%$, and $35 \%$ of total number of vehicles) should be calculated and analyzed; Figure 1 shows the results.

It is clearly shown in Figure 1 that the number of charging stations increases linearly with the increase of the number of EVs, and the average distance between the charging stations becomes shorter with the increase of the number of EVs. Therefore, if the number of EVs is continually expanding, the layout of charging stations would be more and more intensive. So it is no more reasonable to meet the needs of intercity road by increasing the number of charging stations. This problem should be solved by taking some other measures such as expanding the scale of charging stations or increasing the serving efficiency.

(3) Electricity consumption of EVs influences the number of charging stations. 
TABLE 6: Data of charging stations in different electricity consumptions.

\begin{tabular}{lccc}
\hline$Q_{1}$ & $Q_{2}$ & $z_{\max }$ & $l_{\min }$ \\
\hline 0.25 & 1.22 & 3.58 & 6.51 \\
0.225 & 1.098 & 3.22 & 7.24 \\
0.2 & 0.976 & 2.86 & 8.15 \\
\hline
\end{tabular}

With the continuous development and progress of battery technology and EV technology, an average of energy consumption per $100 \mathrm{~km}$ of EVs reduced by $10 \%$ or $20 \%$ energy saving ratio is possible. So the influence on the number of charging stations under the condition of different energy consumptions should be taken into consideration. It is assumed that other parameters are constant values, and the numbers of charging stations are calculated, respectively, when the electricity consumption of EVs is decreased by $10 \%$ and $20 \%$. The result is shown in Table 6 .

Table 6 indicates that the maximum permitted number of charging stations is reduced by 0.52 and 0.48 with the reduction of the electricity consumption of EVs. The analysis shows that the energy consumption of EVs decreasing by $10 \%$ may lead to the reduction of charging stations by $14.53 \%$ and $14.90 \%$, respectively.

(4) Different grades of charging stations influences the number of charging stations along intercity road.

According to "Technical specifications of electricity supply and assurance for electric vehicle: electric vehicle charging station" [24], the charging stations are divided into four grades based on the distribution capacity and service capabilities. Different grades of charging stations have different daily electricity sales which will influence the layout of charging stations. Assuming that other parameters are constant values, the maximum permitted number of charging stations and the average distance between charging stations are calculated, respectively, under the condition of the second grade and the fourth grade of charging stations. The result is in Table 7, compared with the data under the condition of third grade of charging stations which has been shown in Section 3.1.2.

It can be seen that different grades of charging stations have different zero profit daily electricity sales. The number of the third grade of charging stations is 1.79 more than that of the second grade, and the number of the fourth grade of charging stations is 5.37 more than that of the third grade. At the same time it is shown that when the zero profit daily electricity sales decrease by $50 \%$ the number of the charging stations increases by $100 \%$, and when the zero profit daily electricity sales decreases by $40 \%$, the number of charging stations increases by $150 \%$.

In conclusion, the proportion of EVs, number of EVs, electricity consumption of EVs, and different grades of charging stations influence the layout of charging stations. Among them, the number of charging stations is the most sensitive factor; if the number of EVs increased by $5 \%$ each time, the number of charging stations would increase by $49 \%$ and $99 \%$, respectively. Therefore, the number of EVs should be taken into serious consideration when making the layout of charging stations.
TABLE 7: Data of charging stations in different grades of charging stations.

\begin{tabular}{lccc}
\hline Grade of charging stations & $W_{0}$ & $z_{\max }$ & $l_{\min }$ \\
\hline II & 12000 & 1.79 & 13.02 \\
III & 6000 & 3.58 & 6.51 \\
V & 2400 & 8.95 & 2.60 \\
\hline
\end{tabular}

TABLE 8: Data of daily oil sales in gas stations.

\begin{tabular}{lcc}
\hline No. & $\begin{array}{c}\text { The number of gas } \\
\text { stations }\end{array}$ & $\begin{array}{c}\text { Daily oil sales per gas stations } \\
\text { (L) }\end{array}$ \\
\hline 1 & 18 & 20000 \\
2 & 90 & 15000 \\
3 & 92 & 5000 \\
\hline
\end{tabular}

TABLE 9: Data of other basic parameters.

\begin{tabular}{lc}
\hline $\begin{array}{l}\text { Item } \\
\text { Fuel consumption per } 100 \text { kilometers of }\end{array}$ & Parameter \\
passenger vehicle & $9 \mathrm{~L} / 100 \mathrm{~km}$ \\
$\begin{array}{l}\text { Fuel consumption per } 100 \text { kilometers of } \\
\text { commercial vehicle } \\
\text { Electricity consumption per } 100 \text { kilometers of } \\
\text { passenger EV }\end{array}$ & $45 \mathrm{~L} / 100 \mathrm{~km}$ \\
$\begin{array}{l}\text { Electricity consumption per } 100 \text { kilometers of } \\
\text { commercial EV }\end{array}$ & $122 \mathrm{kWh} / 100 \mathrm{~km}$ \\
$\begin{array}{l}\text { The number of the vehicle type } \\
\begin{array}{l}\text { Proportion of the passenger vehicle } \\
\text { Proportion of the commercial vehicle } \\
\text { The proportion of the user charging in charging } \\
\text { stations }\end{array}\end{array}$ \\
$\begin{array}{l}\text { Zero profit daily electricity sales of a charging } \\
\text { station }\end{array}$ & 2 \\
$\begin{array}{l}\text { Expected daily electricity sales of a charging } \\
\text { station }\end{array}$ & 0.8 \\
\hline
\end{tabular}

\subsection{Example of the Layout of Charging Stations in a Certain Area}

3.2.1. Settings of Basic Parameters. Suppose that there are 200 gas stations in an urban area [25]. The data of daily oil sales in gas stations are shown in Table 8, and the data of other basic parameters are shown in Table 9.

3.2.2. Calculations of the Number of Charging Stations in a Certain Area. According to (12), the scale factor of the oil consumption and the electricity consumption of passenger vehicles is calculated as $I_{1}=2.78$, and the scale factor of the oil consumption and the electricity consumption of commercial vehicles is figured out as $I_{2}=2.71$. The scale factor of the oil consumption and the electricity consumption in the corresponding gas stations and charging stations is figured out according to (13), and then all the data of daily oil sales in gas stations and the data of daily electricity sales in the charging stations can be worked out as Table 10 shows. 
TABLE 10: Data of daily electricity sales in the charging stations.

\begin{tabular}{lcccc}
\hline No. & The number of gas STs & Daily oil sales per gas STs (L) & $\begin{array}{c}\text { Corresponding daily } \\
\text { electricity sales (kWh) }\end{array}$ & $\begin{array}{c}\text { Corresponding total daily } \\
\text { electricity sales (kWh) }\end{array}$ \\
\hline 1 & 18 & 20000 & 38780 & 698040 \\
2 & 90 & 15000 & 29085 & 2617650 \\
3 & 92 & 5000 & 9695 & 891940 \\
\hline
\end{tabular}

The total daily electricity sales in this area is worked out as $E=4207630 \mathrm{kWh}$. The maximum number of charging stations is calculated as $z_{\max }=4207630 / 9000=467.51$, and it could be rounded up to an integer $\left(z_{\max }=468\right)$. The defined amount of charging stations is calculated as $z_{j y}=4207630 /$ $12000=350.64$, and it could be rounded up to an integer $\left(z_{j y}=351\right)$.

The result indicates that an ideal program of building urban charging stations can be provided according to the quantitative model of charging stations in a certain area.

\subsubsection{Analysis of Influencing Factors on the Number of the} Charging Stations in a Certain Area. (1) Vehicle type proportion influences the number of charging stations in a certain area.

Assuming that other parameters are constant values, the numbers of charging stations are calculated, respectively, when the proportions of passenger vehicles and commercial vehicles are $9: 1$ and $7: 3$. Table 11 shows the consequence which also demonstrates the corresponding data in Section 3.2.2.

Table 11 shows that when the proportion of commercial vehicles increases by $10 \%$, the maximum number of charging stations decreases by 0 and 2, respectively, the same as the defined amount of charging stations. It is obvious that the proportion of vehicle type has little influence the number of charging stations.

(2) Electricity consumption of EVs influences the number of charging stations in a certain area. According to the schemes described in Section 3.1.3 (3), the numbers of charging stations are calculated, respectively, when the electricity consumption of EVs decreased by $10 \%$ and $20 \%$. The result in shown in Table 12.

Table 12 indicates that the electricity consumption and the number of charging stations are positively correlated. With the electricity consumption decreasing by $10 \%$ each time, the maximum number of charging stations decreases by 47 (10\% in proportion), and defined amount of charging stations deduced by 31 (11.2\% in proportion).

(3) Different grades of charging stations influence the number of charging stations in a certain area.

Assuming that other parameters are constant values, the number of charging stations is calculated in different grades of charging stations. The data is shown in Table 13. Taking different construction costs between the same grades of urban charging stations and intercity charging stations and other factors into consideration, the data of zero profit daily electricity sales in Table 13 and that in Section $3.1 .3(4)$ is different.
TABLE 11: Data of charging stations in different proportions of vehicle type.

\begin{tabular}{lcc}
\hline $\begin{array}{l}\text { Proportion of } \\
\text { vehicle type }\end{array}$ & $\begin{array}{c}\text { Maximum permitted } \\
\text { number of charging } \\
\text { stations }\end{array}$ & $\begin{array}{c}\text { Defined amount of } \\
\text { charging stations }\end{array}$ \\
\hline $9: 1$ & 468 & 351 \\
$4: 1$ & 468 & 351 \\
$7: 3$ & 466 & 349 \\
\hline
\end{tabular}

TABLE 12: Data of charging stations in different electricity consumptions.

\begin{tabular}{lcc}
\hline $\begin{array}{l}\text { The decreased } \\
\text { proportion of electricity } \\
\text { consumption }\end{array}$ & $\begin{array}{c}\text { Maximum } \\
\text { permitted number } \\
\text { of charging stations }\end{array}$ & $\begin{array}{c}\text { Defined amount of } \\
\text { charging stations }\end{array}$ \\
\hline 0 & 468 & 351 \\
$10 \%$ & 421 & 316 \\
$20 \%$ & 374 & 285 \\
\hline
\end{tabular}

TABLE 13: Data of charging stations in different grades of charging stations.

\begin{tabular}{lccc}
\hline $\begin{array}{l}\text { Grade of charging } \\
\text { station }\end{array}$ & $W_{0}$ & $\begin{array}{c}\text { Maximum } \\
\text { permitted number } \\
\text { of charging stations }\end{array}$ & $\begin{array}{c}\text { Defined amount } \\
\text { of charging } \\
\text { stations }\end{array}$ \\
\hline II & 18000 & 234 & 176 \\
III & 9000 & 468 & 351 \\
V & 3600 & 1168 & 878 \\
\hline
\end{tabular}

It can be seen that when the zero profit daily electricity sales decreases by $50 \%$ both the maximum permitted number of charging stations and defined amount of charging stations increase by $100 \%$ and when the zero profit daily electricity sales decrease by $40 \%$ both the maximum permitted number of charging stations and defined amount of charging stations increase by $150 \%$. This law is corresponded with the one in Section 3.1.3 (4). So the influence of the number of charging stations is significant due to the conditions of different grades of charging stations.

This part analyzes the influence of proportion of vehicle types, electricity consumption of EVs, and the grades of charging stations on the number of charging stations in a certain area. Among them, the change of proportion of vehicle types has little effect on the number of charging stations. If the electricity consumption is decreased by $10 \%$, the number of charging stations would reduce by $10 \%$ or so. The sensitivity factor is the grades of charging stations. If the zero profit daily electricity sales decreased by $50 \%$, the 
number of charging stations could reduce by $100 \%$. When future plans for the construction of charging stations are actually made, the grades of charging stations and the serving capabilities should be taken into account, and at the same time, the impact of energy consumption of EVs should not be ignored.

\section{Conclusions}

(1) With energy equivalent substitution as the basic principle, functions and energy supply features of the charging stations are comprehensively considered to conduct influencing factor analysis of quantity model of the linear roads and fixed area charging stations, and results show that the model is applicable to the optimization calculation of the charging stations of the electric vehicles.

(2) The analysis of model proportion, number of electric vehicles, electric vehicles power consumption, and other influencing factors of the number of charging stations show that the proportion change of the models of vehicles will not become the main influencing factor of the number of the charging stations in a fixed area. With the number of EVs increasing by $5 \%$, the maximum number of charging stations would have a linear growth of about 50\%. The energy consumption of EVs decrease by $10 \%$ may lead to the reduction of charging stations by at least $14 \%$. And the zero profit daily electricity saleing are an important factor for the number of the charging stations. With the electricity consumption decreasing by $10 \%$ each time, the maximum number of charging stations decreases $10 \%$ in proportion.

(3) At present, the future development should be taken into account when incubating a charging stations plan. As different scales of charging stations have different serving capabilities, some measures should be taken to enhance their service capabilities, such as decreasing the service time per vehicle are improving the technology and the quality of services. The growing number of EVs and the expanded scale of charging stations should also be taken into consideration.

\section{Acknowledgments}

The project was supported by the National Natural Science Foundation of China (61004092), National High Technology Research and Development Program of China (2011AA11A251), and Research Foundation of National Engineering Laboratory for Electric Vehicles (2012-NELEV-03).

\section{References}

[1] Q. Guo, J. Han, M. Yoon, and G. Jang, "A study of economic dispatch with emission constraint in smart grid including wind turbines and electric vehicles," in Proceedings of the IEEE Vehicle Power and Propulsion Conference, pp. 1002-1005, 2012.

[2] M. Inoue, "Environment friendly new energy supply system," IEEJ Transactions on Electrical and Electronic Engineering, vol. 2, no. 1, pp. 39-43, 2007.

[3] M. Etezadi-Amoli, K. Choma, and J. Stefani, "Rapid-charge electric-vehicle stations," IEEE Transactions on Power Delivery, vol. 25, no. 3, pp. 1883-1887, 2010.
[4] M. Yilmaz and P. T. Krein, "Review of battery charger topologies, charging power levels, and infrastructure for plug-in electric and hybrid vehicles," IEEE Transactions on Power Electronics, vol. 28, no. 5, pp. 2151-2168, 2013.

[5] Z. Liu, F. Wen, and G. Ledwich, "Optimal planning of electricvehicle charging stations in distribution systems," IEEE Transactions on Power Delivery, vol. 28, no. 1, pp. 102-110, 2013.

[6] M. Simonov, "Mastering cooperation: electric vehicle and smart grid," in Proceedings of the 11th International Conference on ITS Telecommunications (ITST '11), pp. 480-485, August 2011.

[7] General Office of the State Council of China, Decision of the State Council on Accelerating the Development of Strategic Emerging Industries, General Office of the State Council of China, Beijing, China, 2010.

[8] A. M. Sharaf and B. Khaki, "Novel switched capacitor-filter compensator for smart grid-electric vehicle charging scheme," in Proceedings of the IEEE International Conference on Smart Grid Engineering (SGE '12), pp. 1-5, 2012.

[9] S. Shahid, K. R. Narumanchi, and D. Gurkan, "Plug-in electric vehicle battery sensor interface in smart grid network for electricity billing," in Proceedings of the IEEE Energy Conversion Congress and Exposition (ECCE '12), pp. 3403-3410, February 2012.

[10] M. Singh, P. Kumar, and I. Kar, "A model of electric vehicle charging station compatibles with vehicle to grid scenario," in Proceedings of the IEEE International Electric Vehicle Conference (IEVC '12), pp. 1-7, 2012.

[11] T. W. Ching, "Design of electric vehicle charging station in Macau," Journal of Asian Electric Vehicles, vol. 9, no. 1, pp. 14531458, 2011.

[12] C. E. Hatton, S. K. Beella, J. C. Brezet et al., "Charging station for urban settings: the design of a product platform for electric vehicle infrastructure in Dutch cities," in Proceedings of the International Battery Hybrid and Fuel Cell Electric Vehicle Symposium and Exhibition, pp. 514-526, 2009.

[13] H. S. Wang, Q. Huang, C. H. Zhang, and A. Xia, "A novel approach for the layout of electric vehicle charging station," in Proceedings of the International Conference on Apperceiving Computing and Intelligence Analysis (ICACIA '10), pp. 64-70, December 2010.

[14] C. S. Revelle and H. A. Eiselt, "Location analysis: a synthesis and survey," European Journal of Operational Research, vol. 165, no. 1, pp. 1-19, 2005.

[15] Z. P. Wang, X. H. Sun, Y. Wang, and L. Y. Liu, "Research on matching theory of EV charging station," Information A, vol. 15, no. 11, pp. 4359-4366, 2012.

[16] W. Johannes, L. Susanne, and K. Alois, "Modelling the development of a regional charging infrastructure for electric vehicles in time and space," European Journal of Transport and Infrastructure Research, vol. 12, no. 4, pp. 391-416, 2012.

[17] J. He, B. X. Zhou, C. Feng et al., "Electric vehicle charging station planning based on multiple-population hybrid genetic algorithm," in Proceedings of the International Conference on Control Engineering and Communication Technology (ICCECT '12), pp. 403-406, 2012.

[18] L. Feng, S. Y. Ge, and H. Liu, "Electric vehicle charging station planning based on weighted voronoi diagram," in Proceedings of the Asia-Pacific Power And Energy Engineering Conference (APPEEC '12), 2012.

[19] G. B. Ning, Z. J. Zhen, P. Wang, Y. Li, and H. X. Yin, "Economic analysis on value chain of taxi fleet with battery-swapping mode 
using multiobjective genetic algorithm," Mathematical Problems in Engineering, vol. 2012, Article ID 175912, 15 pages, 2012.

[20] Y. Wang and C. Lin, "Locating road-vehicle refueling stations," Transportation Research E, vol. 45, no. 5, pp. 821-829, 2009.

[21] L. Zhang, "Application of data of traffic volume in highway station," Transportation Information Industry, pp. 85-86, 2009.

[22] W. Chen, J. Guo, K. You, and Z. Zhen, "Energy-saving \& emission reduction effects prospecting of ten cites \& thousand units demonstration operation," Automobile \& Parts, pp. 34-35, 2010.

[23] W. J. Sweeting, A. R. Hutchinson, and S. D. Savage, "Factors affecting electric vehicle energy consumption," International Journal of Sustainable Engineering, vol. 4, no. 3, pp. 192-201, 2011.

[24] Beijing Municipal Administration of Quality and Technology Supervision, DBll/Z 728. 2010, Technical Specifications of Electricity Supply and Assurance for Electric Vehicle: Electric Vehicle Charging Station, Beijing Municipal Administration of Quality and Technology Supervision, Beijing, China, 2010.

[25] C. Wang, "Exploration on principles and strategies of rational distribution of gas stations of national oil companies," Peroleum \& Petrochemical Today, vol. 16, no. 11, pp. 30-34, 2008. 


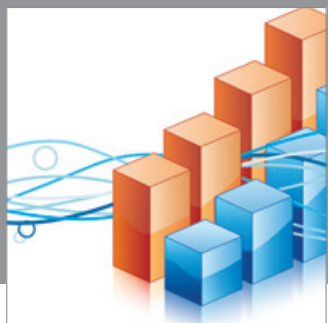

Advances in

Operations Research

mansans

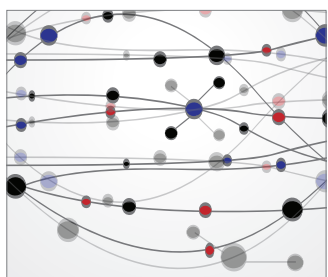

The Scientific World Journal
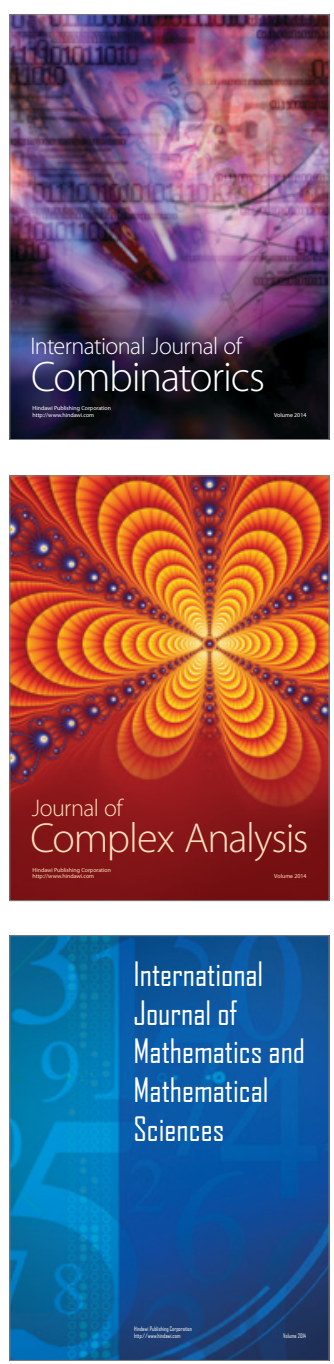
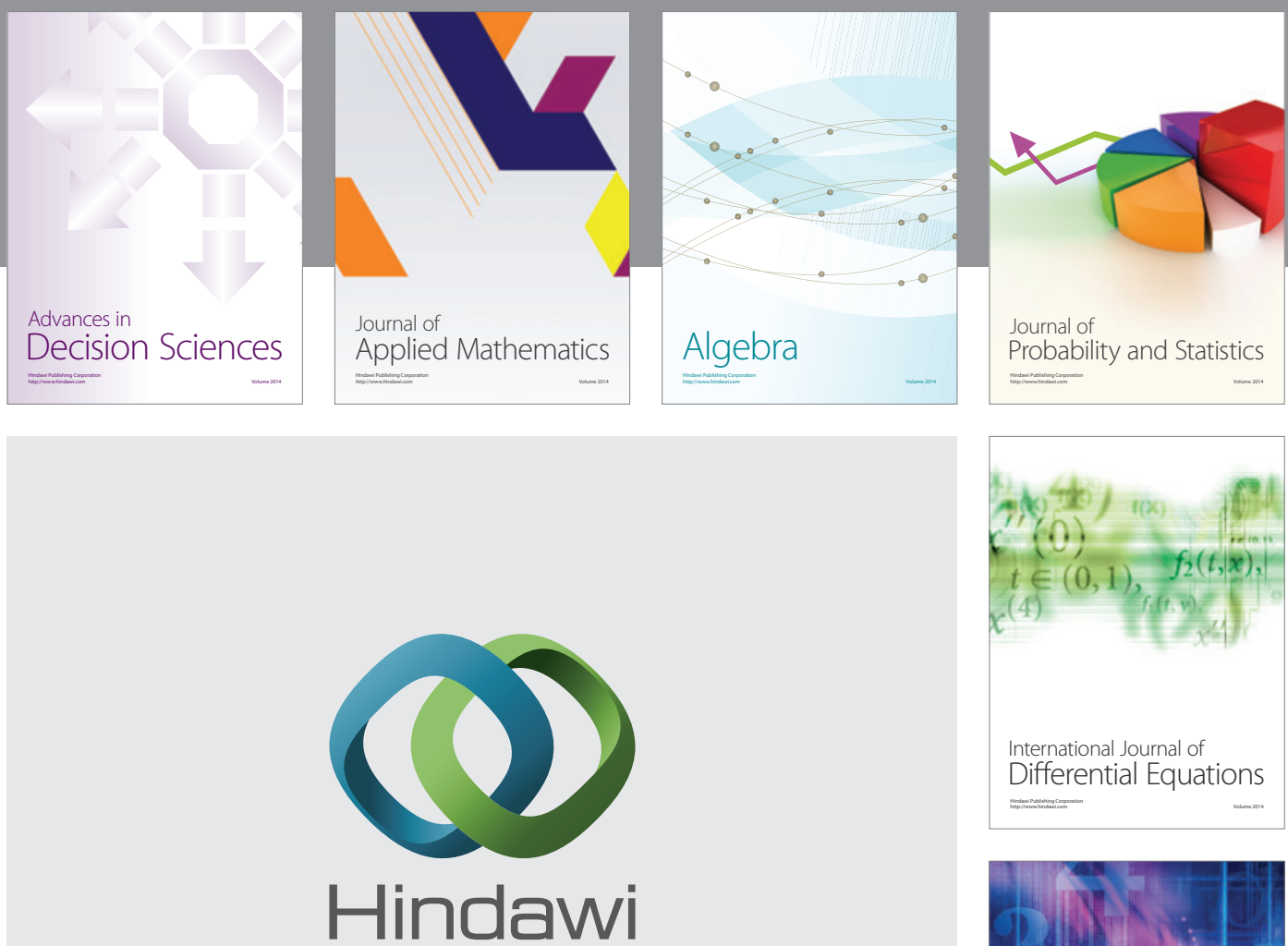

Submit your manuscripts at http://www.hindawi.com
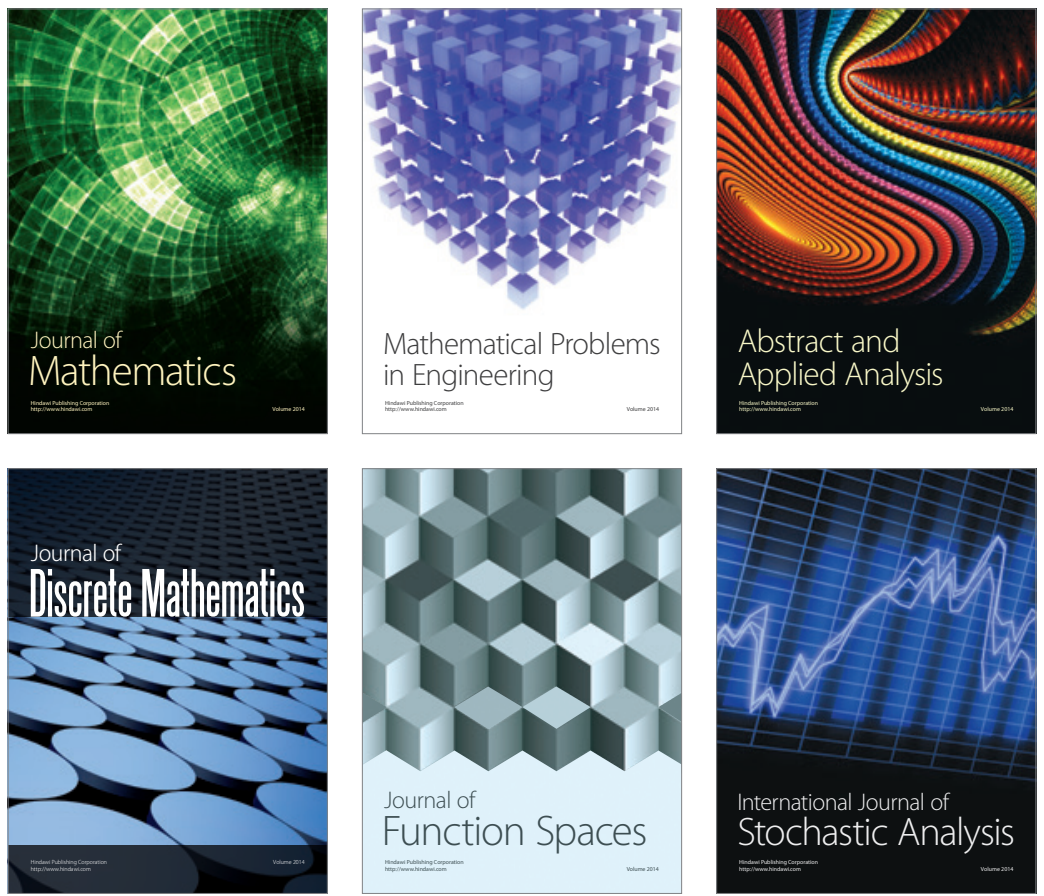

Journal of

Function Spaces

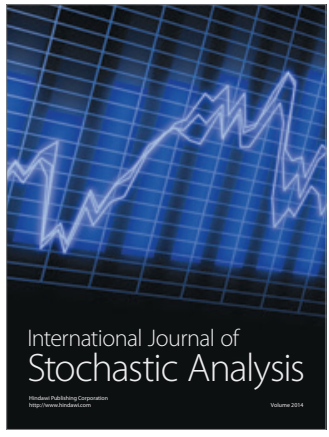

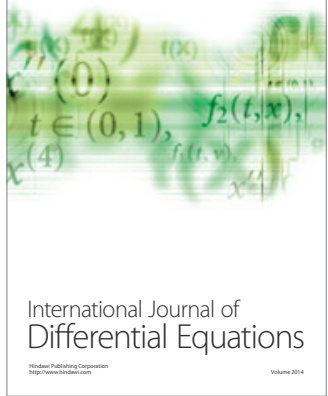
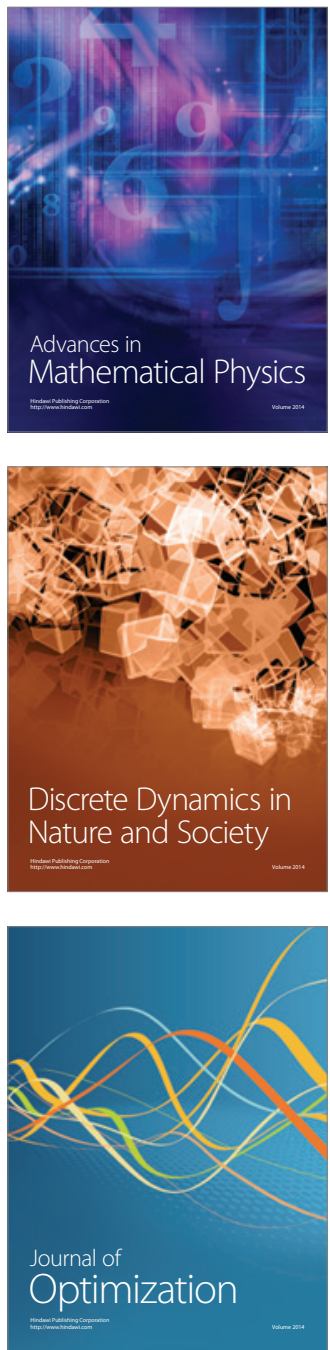